\title{
EL MOVIMIENTO DE PENSIONISTAS, FENÓMENO SINGULAR DE LARGO ALCANCE
}

\author{
Pensioners' movement, a long-range phenomenon
}

\author{
Luis Alejos Escarpe*
}

Sociólogo y pensionista

\section{RESUMEN}

La defensa del sistema público de pensiones aporta aspectos tan novedosos que constituye un fenómeno singular. Destacan en particular el plano organizativo, los escenarios donde se desarrolla y la prolongada duración del conflicto. Para encontrar experiencias con alguna similitud habría que remontarse al movimiento obrero durante el periodo franquista y la Transición. No es casual que quienes dinamizan esa lucha estuviesen entonces en plena juventud y se comprometiesen en diversas causas. Las movilizaciones de pensionistas constituyen un acontecimiento social digno de estudio. Su problemática ya ha sido tratada en cursos de verano universitarios. Este artículo analiza sus orígenes y trayectoria con un enfoque sociológico, sin pretender abarcar aspectos que atañen a la política, al derecho y la economía.

Palabras clave: pensionistas, reivindicaciones, concentraciones, organización.

\section{ABSTRACT}

The defense of the public system of retirement pensions provides such novel aspects that it constitutes an unique phenomenon. Its organization, the scenes where it is carried out and the long duration of the conflict are its most relevant features. To find similar experiences we should go back to the times of the workers movement in the Franco regime and in the transition to democracy. It is not a coincidence that those who revitalize this struggle were then in their youth and also committed to several causes. Pensioners' mobilizations are a great occurrence worthy of being considered. Its problems have already been addressed in university summer courses. This article analyses its origins and its career from a sociological perspective, not intending to include aspects concerning politics, law or economics.

Keywords: pensioners, recognitions, demonstrations, organization.

* Correspondencia a: Luis Alejos Escarpe. Calle Urazurrutia, 9-3. ${ }^{\circ}$ izquierda. 48003 Bilbao-Vizcaya - kalejos@hotmail. com - https://orcid.org/0000-0003-3955-1945

Cómo citar: Alejos Escarpe, Luis. (2018). «El movimiento de pensionistas, fenómeno singular de largo alcance»; Lan Harremanak, 40, 31-48. (https://doi.org/10.1387/lan-harremanak.20327).

Recibido: 6 noviembre, 2018; aceptado: 30 noviembre, 2018.

ISSN 1575-7048 - elSSN 2444-5819 / @ 2018 UPV/EHU 


\section{SUMARIO}

1. Consideraciones previas.-2. Movimiento social de pensionistas. 2.1. ¿El activismo de los pensionistas es un movimiento social?.-3. El asociacionismo en el colectivo de pensionistas. 3.1. Asociacionismo de ámbito estatal. 3.2. Asociacionismo en Euskadi y Navarra.-4. Movimiento de Pensionistas de Bizkaia (MPB). 4.1. Asociaciones integradas en el MPB. 4.2. Ámbito territorial del MPB. 4.3. Modelo organizativo del MPB.-5. Unidad en la diversidad. 5.1. Dilemas internos. 5.2. La cuestión del liderazgo. 5.3. Perfil de activista de movimientos sociales.-6. El MPB y las organizaciones sindicales.-7. El MPB y los partidos políticos.-8. Reivindicaciones del movimiento de pensionistas 8.1. Posicionamientos sobre la reivindicación de $1.080 €$ y las EPSV. 8.2. Plataforma reivindicativa básica del MPB.-9. Defensa del bien común.-10. Rejuvenecer en la edad tardía.-11. De las coordinadoras de fábricas al movimiento de pensionistas.-12. El conflicto continúa, la lucha sigue.-13. Claves del conflicto.-14. Publicaciones citadas en el texto.

«No veo por ningún lado la crisis de las pensiones.»

Miren Etxezarreta

\section{Consideraciones previas}

Dado que las movilizaciones de pensionistas constituyen un fenómeno reciente e inesperado, sin antecedentes ni episodios anteriores, no es posible documentarlo ni contrastarlo con otras fuentes. Tan solo cabe verificar si merece la consideración de movimiento social. Sin ser previsible que estallase el conflicto, al tratarse de un colectivo disperso y sin trayectoria reivindicativa, quienes se dedican a estudiar la problemática de las pensiones públicas sí venían destacando la posibilidad de esas acciones colectivas. Veamos algunos ejemplos:

La reforma de las pensiones ha pasado sigilosa por encima de la sociedad española, sin que apenas se haya expresado el conflicto social latente en ella, pese a que todos los sondeos reflejaban un fuerte rechazo a algunas de sus medidas más conocidas. A ello ha contribuido, sin duda, el apoyo que ha recibido de las dos principales centrales sindicales, que no ha convencido pero si ha desactivado posibles respuestas, pero también el contexto de crisis en que se ha producido el rápido cambio legislativo. (Sáenz, 2011:162)

Ante la dureza que supone la propuesta actual (reforma de 2013), que además viene cuando justo se están experimentando las de la reforma de 2011, es posible que la opinión pública reaccione con más fuerza, pero todavía no se percibe una actitud 
de resistencia, rechazo y actuación como serían necesarias para por lo menos intentar frenar este nuevo y amplio ataque. (Etxezarreta 2013:56)

Una característica sorprendente de estas reformas es que, a pesar de conllevar reducciones drásticas de las pensiones, se han realizado sin demasiadas protestas de los sindicatos y agentes sociales. Quizá sea porque las reformas se han hecho en medio de una crisis o quizá porque los efectos son de largo plazo. Pero la realidad es que las reformas han sido aceptadas sin casi oposición. (Zubiri, 2015:260)

\section{Movimiento social de pensionistas}

No resulta fácil datar el nacimiento de la mayoría de los movimientos sociales, sea el feminista, el ecologista o el antimilitarista. Sin embargo, el movimiento de pensionis-tas surge un día concreto, a una hora determinada, en un lugar preciso, respondiendo a una cita: «lunes 15 de enero de 2018, a las 12 del mediodía, en el Ayuntamiento de Bilbao, defenderemos nuestras pensiones. Pásalo». Este escueto texto u otro similar es el mensaje que circuló a modo de convocatoria por las redes sociales, logrando reunir a varios cientos de personas, sin brecha digital en la edad madura.

Fue un acto improvisado, no autorizado. Entre quienes asistieron nadie ha podido precisar cómo se promovió. Intervinieron varias personas que, sin utilizar megáfono, insistieron en la necesidad de pasar la voz para volver a concentrarse el lunes siguiente. Una semana después la concentración estaba autorizada, se disponía de megafonía y acudió un millar de personas. En fechas sucesivas la participación siguió creciendo, hasta alcanzar una cifra que ronda las 5.000 personas. Mientras esas escenas se desarrollaban en Bilbao, lo mismo ocurría frente a los ayuntamientos de Barakaldo, Santurtzi, Basauri y muchas otras localidades de Bizkaia.

El escenario de las concentraciones de pensionistas no resultó del agrado del Alcalde de Bilbao: «le «incomoda» que se manifiesten semanalmente junto al Ayuntamiento "teniendo a la Delegación de Gobierno como eje» de sus protestas» (Europa Press 12/03/2018). Puede que el Sr. Aburto haya cambiado de opinión. Las concentraciones de pensionistas han convertido en un símbolo la fachada del ayuntamiento y la escultural esfera ovoide de Oteiza que cada lunes destaca sobre la muchedumbre.

\section{1. ¿El activismo de los pensionistas es un movimiento social?}

Despejaremos las dudas basándonos en sus características:

Un movimiento social es una forma colectiva de acción (reclamar pensiones dignas), y la existencia de una acción colectiva implica la preexistencia de un conflicto (pérdida del poder adquisitivo de las pensiones)». «Surge, pues, porque existen caren- 
cias organizativas (los pensionistas no se sienten representados por los sindicatos)». Creen que los problemas, a favor de cuya solución ha decidido movilizarse, deben solucionarse de forma participativa, igualitaria y cooperativa (concentraciones, manifestaciones). (Ibarra, Grau 2000:02)

Los tres rasgos que conforman esos marcos, potencialmente impulsores de una decisión de movilización, son los siguientes. Sentimiento de que algo injusto está ocurriendo y de que hay alguien culpable de esa injusticia (gobierno); sentimiento de que esa injusticia recae sobre un colectivo con el que el individuo se siente solidario, de que existe un "nosotros», una identidad colectiva (pensionistas), violada por esos «otros» culpables; y finalmente, sentimiento de que es posible, en una movilización colectiva, vencer - juntos - esa injusticia (concentraciones). (Ibarra, Grau, 2000:03)

Las movilizaciones de pensionistas poseen los elementos definitorios de cualquier movimiento social, volveremos a corroborarlo en referencia al perfil de los activistas y al modelo organizativo de dicho movimiento.

\section{El asociacionismo en el colectivo de pensionistas}

Hay multitud de asociaciones de pensionistas, la mayoría son asistenciales. Hasta el inicio de las movilizaciones del año en curso, si exceptuamos las agrupaciones de pensionistas promovidas por sindicatos, apenas había plataformas reivindicativas.

Siendo características esenciales de las asociaciones de pensionistas la pluralidad y la dispersión, existe interacción y reciprocidad entre movilizaciones a nivel estatal y en Euskadi. Dos ejemplos lo evidencian: en el País Vasco se asumió el llamamiento promovido por la Coordinadora Estatal (COESPE) el 5 de mayo, y viceversa, la COESPE apoyó la movilización impulsada desde Euskadi tres semanas después, el 26 del mismo mes. Ocurre otro tanto con la manifestación promovida por asociaciones del País Vasco y Navarra para el 15 de diciembre, la COESPE convocará el mismo día en el conjunto del Estado.

\subsection{Asociacionismo de ámbito estatal}

Al margen de los sindicatos, dos organismos sin vinculación orgánica agrupan a la generalidad de las asociaciones reivindicativas representativas:

\section{Coordinadora Estatal por la Defensa del Sistema Público de Pensiones (COESPE)}

Se crea en 2016, está constituida por unas 200 plataformas de pensionistas de todas las Comunidades Autónomas. Se han integrado en ella asociaciones como la catalana Marea Pensionista o sectores del movimiento Yayoflautas, sur- 
gido del 15-M. Tiene carácter apartidista y asindical, funcionamiento asambleario, autonomía territorial. El factor aglutinador de esa red asociativa es su tabla reivindicativa.

\section{Mesa Estatal por el Blindaje de las Pensiones (MERP)}

Principal reivindicación: «Las pensiones públicas deben elevarse en nuestra Carta Magna a la categoría de derecho fundamental, prohibiendo su privatización y la pérdida de poder adquisitivo.» Destaca por su alcance mediático y el apoyo de personalidades de diversos ámbitos. Agrupa 250 colectivos, incluyendo sindicatos y partidos políticos.

\subsection{Asociacionismo en Euskadi y Navarra}

En las comunidades autónomas del País Vasco y de Navarra el asociacionismo reivindicativo es más amplio y está más consolidado que en el Estado. Se caracteriza por la dispersión, no coincide con el modelo unitario de Bizkaia. Hay unidad de acción, aunque no agrupa a todas las plataformas. Se convocan reuniones periódicas para analizar la situación y planificar movilizaciones coordinadas, suelen ser manifestaciones simultáneas en las cuatro capitales.

\section{Movimiento de Pensionistas de Bizkaia (MPB)}

Se cimenta sobre las concentraciones y funciona como equipo de trabajo. Integrado al comienzo por unas 30 personas, en la actualidad se ha duplicado. Se reúne cada semana, en general los miércoles, casi siempre en el centro cívico La Bolsa de Bilbao. Programa y coordina acciones, elabora y difunde declaraciones, informando de todo ello en las concentraciones locales y a través de la prensa.

Dicho equipo se constituyó de forma espontánea, lo mismo que surgió el movimiento de pensionistas. Se participa a nivel personal, sin ser preciso formar parte de una asociación. Basta acudir a las concentraciones de cualquier población. Otra función del MPB es zanjar diferencias de todo tipo: personales, organizativas o ideológicas, para que no se trasladen a las concentraciones. Este problema afecta sobre todo a Bilbao, no se suele dar en el resto de municipios de Bizkaia.

\subsection{Asociaciones integradas en el MPB}

En Bizkaia, como en Euskadi y el conjunto del Estado, abundan las asociaciones de pensionistas, sobre todo de carácter asistencial y cultural. Tan 
solo en Bilbao hay 53. En proporción a su número, son pocas las asociaciones que participan en actividades reivindicativas. Dado que las organizaciones sindicales suelen tener federaciones o secciones de pensionistas, sorprende que ELA, sindicato mayoritario en todos los territorios de Euskadi, apoye las movilizaciones sin considerar necesario mantener una representación directa en el MPB.

- Nagusiak: es la asociación mayoritaria, más veterana y menos ideologizada. De hecho es un organismo asistencial institucional que se suma a la acción reivindicativa. Agrupa 138 asociaciones de todos los municipios de Bizkaia, declarando 50.000 asociados.

- Pentsionistak Martxan: promovido por la izquierda abertzale, es el grupo más estructurado y activo. Insiste en la acción unitaria en el conjunto del País Vasco y Navarra. Sus aspiraciones soberanistas son compatibles con el apoyo a reivindicaciones y movilizaciones de ámbito estatal.

- Coordinadora de Pensionistas de Bizkaia: pertenece a la Coordinadora Estatal (COESPE). Varias plataformas municipales de Bizkaia forman parte de ella. Su principal objetivo es la defensa del sistema público de pensiones. Su seña de identidad en el País Vasco es la oposición a la proliferación de las EPSV de empleo.

- Personas Jubiladas de Bizkaia (PJB): surge en Bilbao. Dado su carácter local, al comienzo la prensa identificaba al MPB con PJB. Utilizando vínculos orgánicos se ha entrevistado con delegaciones de Podemos y del PSOE. Estuvo adscrita a la Coordinadora Estatal (COESPE), desvinculándose posteriormente.

- Movimiento 15-M: agrupa a pensionistas que participaron en el Movimiento $15-\mathrm{M}$.

- Asociación de Jubilados y Pensionistas por la Democracia de Bizkaia, vinculada a la Federación de Jubilados y Pensionistas de CCOO.

— Unión de Pensionistas y Jubilados de UGT (UPJ-UGT).

En la mayoría de las plataformas y coordinadoras de pueblos no hay incidencia directa de las asociaciones, ese rasgo destaca sobre todo en Bilbao.

\section{2. Ámbito territorial del MPB}

Listado no exhaustivo de poblaciones representadas en el MPB:

Bilbao, Barakaldo, Basauri, Sestao, Portugalete, Santurtzi, Trapagaran, Sopuerta, Ortuella, Abanto y Zierbena, Getxo, Leioa, Erandio, Sopela, Galdakao, Zornotza, Durango, Yurreta, Berriz, Ermua, Zaldibar, Zornotza...

Otras poblaciones donde se realizan concentraciones sin participar en las reuniones del MPB: Mungia, Gernika, Bermeo, Balmaseda, Lekeitio, Derio... 


\subsection{Modelo organizativo del MPB}

El Movimiento de Pensionistas de Bizkaia es un equipo de coordinación dedicado a planificar y gestionar acciones reivindicativas. Dado que la lucha surge de forma espontánea y se expande de la misma manera, el MPB constituye un movimiento social de base, coordinado a nivel horizontal, con autonomía municipal. Es unitario y plural, integra a personas de sensibilidad nacionalista y estatal, gente afín a los sindicatos o que los rechazan. Se respeta la igualdad, en la representación tienen prioridad las mujeres. Hay sensibilidad hacia la problemática lingüística, se procura que haya intervenciones en euskera y que los documentos sean bilingües. No existe estructura vertical, no hay portavoces oficiales. Las portavocías son rotatorias, se eligen en cada acto. No hay liderazgos individuales, las movilizaciones se secundan porque las convocatorias llevan la firma del MPB.

La participación en ese grupo de coordinación es voluntaria e individual, sin ser preciso pertenecer a ninguna asociación. No hay delegaciones de plataformas ni de asociaciones, quienes lo integran carecen de representatividad formal. Al no ser posible establecer criterios de proporcionalidad, las decisiones relevantes se toman por unanimidad, tras arduos debates. Hay estabilidad en la participación, aunque la asistencia fluctúa entre 40 y 60 personas. La representación más numerosa procede de Bilbao, siendo la más ideologizada y plural. Las delegaciones de los pueblos resultan más homogéneas. Las características básicas del MPB son: composición plural, autonomía local, liderazgo compartido y decisiones por consenso.

Conforme corresponde a un fenómeno social que surge y se expande de forma espontánea, el MPB carece de estructura orgánica. Sin embargo, está coordinado y tiene normas de funcionamiento basadas en el modelo asambleario.

los movimientos tienen una notable capacidad de informalidad organizativa, métodos no convencionales, redes preexistentes disponibles para canalizar fácilmente las tensiones emergentes. (Ibarra, Grau 2000:04)

\section{Unidad en la diversidad}

La composición del Movimiento de Pensionistas de Bizkaia además de plural es muy compleja. Tanto, que para describir sus características es preciso basarse, a falta de fuentes documentales precisas, en analizar comportamientos. Insistimos en que la incorporación al MPB y a las diversas plataformas o asociaciones que lo integran es voluntaria e individual. No siendo posible cuantificar la representatividad de sus componentes, ni el liderazgo de sus miembros. Para 
acercarse a la realidad hay que observar lo que acontece cada lunes en las concentraciones (sobre todo en la de Bilbao) y los miércoles en la asamblea abierta donde se coordinan las actividades.

\subsection{Dilemas internos}

El primer escollo que surgió al crearse el MPB como equipo coordinador de la lucha fue la presencia de sindicatos (UGT y CCOO). Se zanjó aceptando, no sin recelos, su integración. Después apareció el protagonismo personal. Se compite por ir en la pan-carta, leer comunicados o intervenir en ruedas de prensa. En los plenos la mayoría de las discusiones están motivadas por la imagen ante los medios de comunicación. Ocurre en Bilbao porque la prensa está concentrada en la capital.

Un punto de fricción es el posicionamiento respecto a los planes de pensiones de empleo (EPSV), implantados en la administración pública vasca y en amplios sectores industriales de Gipuzkoa. En la promoción y gestión de las EPSV están implicados los cuatro sindicatos mayoritarios. En el MPB se ha conseguido llegar a un acuerdo para reclamar que se supriman las bonificaciones fiscales.

La puesta en marcha de la mesa de concertación puede reavivar el conflicto sindical, si quedan fuera los sindicatos de ámbito autonómico. Se puede llegar a cuestionar la legitimidad para negociar sin representar al conjunto de los pensionistas y careciendo de la capacidad de movilización que tienen las plataformas. Está por ver si CCOO y UGT defienden en la negociación las reivindicaciones que ahora asumen o toleran: demanda de $1.080 €$ de pensión mínima, derogación de la reforma laboral del PP (2013) y también la que ellos firmaron con el anterior gobierno del PSOE (2011).

Otro motivo de disenso es la «caja única de las pensiones». Pentsionistak Martxan reclama un sistema de pensiones propio en Hego Euskal Herria. El problema se neutraliza obviando el modelo de pensiones en la plataforma reivindicativa. Si no se respeta ese acuerdo tácito hay tensiones. El manifiesto conjunto de asociaciones de Navarra y de Euskadi hecho público el 18/10/18 declara: "... en relación con las Instituciones Vascas, no se libera por Ley su capacidad para ejercer competencias a la hora de decidir su techo de gasto y dignificar las pensiones a las que el Estado renuncia». Tal posicionamiento motivó una ardua polémica. Algunas plataformas se negaron a difundirlo. Hechos de ese tipo ponen a prueba el frágil equilibrio del MPB.

\subsection{La cuestión del liderazgo}

Toda organización, aunque tenga una estructura mínima, como los movimientos sociales, tiende a la jerarquización. Está ocurriendo entre quienes integran el MPB, pese a carecer de representatividad formal, dado que no se ha efec- 
tuado ningún nombramiento o designación. Queda dicho que ni siquiera hay portavoces oficiales. En las concentraciones de Bilbao un elemento tan material como el control de la megafonía es un instrumento de poder que determina el orden y la duración de las intervenciones, facilitando además el acceso a los medios de comunicación. Esas circunstancias establecen un rango, una jerarquía, aunque el liderazgo sea colectivo. Las movilizaciones se secundan porque las convoca el MPB, no se responde al llamamiento de nadie con cualidades carismáticas.

\subsection{Perfil de activista de movimientos sociales}

Ese individuo que siente solidariamente la injusticia y que cree que a través de una movilización colectiva y solidaria es posible eliminarla (Ibarra, Grau 2000:04).

Además de la conciencia social intervienen otros elementos: la militancia política, la simpatía ideológica e incluso el afán de protagonismo personal. Quienes integran el MPB son conscientes de que si se exteriorizasen los conflictos internos se disolverían las concentraciones. Uno de los cometidos de las reuniones es ejercer la función de «tanque de tormentas» para evitar catástrofes.

\section{El MPB y las organizaciones sindicales}

La relación entre las organizaciones sindicales y los movimientos sociales, antańo el obrero, ahora el de pensionistas, siempre ha sido de mutuo recelo. Esa desconfianza se basa sobre todo en la defensa de las reivindicaciones. Parte de las aspiraciones que motivan un conflicto llegan a la mesa de negociación a través de los sindicatos. Son demandas maximalistas que se recortan en los acuerdos establecidos entre gobierno, patronal y sindicatos. Puede ocurrir con la consigna de la pensión mínima de $1.080 €$ que cohesiona y moviliza al colectivo de pensionistas.

Uno de los elementos que explican el éxito del MPB es la pluralidad lograda integrando sindicatos. Aunque solo participan UGT y CCOO, cabe interpretar que Pensionistak Martxan representa a LAB, sorprendiendo la ausencia de ELA, que no considera necesaria su presencia directa en el MPB. Sin embargo, apoya todas las movilizaciones. Lo evidencia su comunicado del 16 de febrero de 2018: "ELA llama a participar en las movilizaciones convocadas por las plataformas de pensionistas».

Los sindicatos tienen menor capacidad de movilización que el MPB. Estando activo el movimiento social, no es probable que tomen iniciativas propias 
sobre pensiones. En Bizkaia, por exigencia expresa de la gente que participa en las movilizaciones, se excluyen símbolos y pancartas con distintivos de organizaciones. Los sindicatos secundan las convocatorias del MPB, dejando al margen las diferencias que provocan su división. Pero la capacidad de interlocución es competencia sindical. Si negocian en exclusiva las organizaciones sindicales de ámbito estatal, se puede reavivar la confrontación, afectando al colectivo de pensionistas.

\section{El MPB y los partidos políticos}

Como cualquier movimiento social, El MPB es apartidista, pese a que se difundan rumores interesados de lo contrario. $\mathrm{Ni}$ en las concentraciones ni en las reuniones se interviene nunca en nombre de ningún partido. No obstante, las personas que participan en las tareas organizativas tienen una ideología definida y hasta militancia política. No podría ser de otra forma, dada la personalidad del activista de movimientos sociales: "... casi siempre esta sensibilidad especial se ha sedimentado a través de una práctica previa». (Ibarra, Grau 2000:04).

En las concentraciones se aprecia confusión al no diferenciar el apartidismo del apoliticismo. En las manifestaciones se puede gritar: "Rajoy dimisión» o «Ni un día más de gobierno del PP», pero no declarar lo evidente: reivindicar pensiones dignas es hacer política. Cabe distinguir la política social de la partidista, pero intentar hacerlo ante una multitud entrańa el riesgo de la incomprensión, sobre todo habiendo gente presta a promover un abucheo si se pronuncia esa palabra proscrita.

Desconciertan tales reacciones mientras se corean consignas de inequívoco alcance político: «Si nos roban las pensiones, lo pagarán en las elecciones». Esta proclama lleva a suponer que las movilizaciones proseguirán hasta mayo del 2019. Conforme se vaya acercando la cita con las urnas, se reclamará a los partidos que incluyan en sus programas electorales las reivindicaciones de los pensionistas, aunque no es probable que se llegue a orientar el voto en una dirección concreta.

Entretanto surgen partidos dispuestos a competir por los votos de nueve millones de pensionistas. El Partido de Jubilados y Pensionistas de España (PJPE) reclama dejar de abonar el IRPF. No es una medida para quienes cobran las pensiones más bajas, pues no dan para pagar impuestos. Tarjeta de presentación de Tercera Edad en Acción, que reniega de las movilizaciones en la calle: "Somos expertos en la gestión, por nuestras actividades empresariales». Tanta demanda por el voto pensionista recuerda el título de la última película de Buñuel: "Ese oscuro objeto del deseo", aunque tiene un indudable interés sociológico y político. 


\section{Reivindicaciones del movimiento de pensionistas}

«Las soluciones a los problemas económicos son políticas, nunca económicas.»

Juan Torres

Las reivindicaciones fundamentales coinciden en todos los territorios. El detonador de las movilizaciones fue la oposición al incremento del 0,25\%, establecido por el Gobierno del PP como «indice de revalorización de las pensiones». Calculado mediante una compleja fórmula, permitiría al gobierno de turno aplicar la subida preferida. El rechazo del 0,25\% parece más que justificado.

La propuesta de un aumento del 0,25\% de suelo no es más que un intento de enmascarar la reducción del valor real de las pensiones para manipular a la opinión pública y facilitar la aceptación del nuevo sistema. (Etxezarreta 2013:53)

La alternativa al 0,25\% viene siendo desde el principio la revalorización anual de las pensiones en función del Índice de Precios al Consumo (IPC) real. Por eso, la mejora incluida en los Presupuestos Generales del Estado (PGE) para 2018 fue declarada insuficiente y no afectó a la participación en las movilizaciones. La propuesta del Gobierno del PSOE de aplicar el IPC real en 2019 tampoco ha convencido, sigue sin estar garantizada por ley o en la Constitución. Como además se reclama una pensión mínima de $1.080 €$, cabe suponer que las movilizaciones proseguirán, confiando en que en la negociación tripartita (gobierno, patronal, sindicatos) o en vísperas de las elecciones de mayo de 2019, haya un compromiso de subida lineal que reduzca las desigualdades entre pensiones bajas y altas.

El colectivo de pensionistas lleva la iniciativa en el plano reivindicativo, de tal modo que ni el anterior gobierno ni el actual consiguen solucionar el conflicto. Entretanto, desde los sectores económicos, políticos y mediáticos que compiten por desprestigiar esa lucha, se acusa a los pensionistas de insolidaridad, al estar planteando, entre otras reclamaciones, pensiones superiores al Salario Mínimo Interprofesional (SMI).

Si se aprobasen los PGE del 2019 con $900 €$ de SMI, las plataformas de pensionistas deberían valorar esta disyuntiva: a) seguir demandando los $1.080 €$ como una reivindicación irrenunciable e impostergable, b) reclamar la equiparación con el SMI, uniendo ambas causas para que avancen al unísono. También se debería valorar si tiene sentido que los pensionistas reclamen un SMI de $1.200 €$, en vez de hacerlo la gente afectada. En cualquier caso, al menos en teoría, la alternativa pasa por:

si se desea evitar un empobrecimiento generalizado de los jubilados futuros, se debe pasar de un sistema como el actual en el que los ingresos determinan los gastos a otro en el que sean los gastos los que determinen los ingresos necesarios. ( $\mathrm{Zu}-$ biri, 2015: 260) 


\subsection{Posicionamientos sobre la reivindicación de $1.080 €$ y las EPSV}

El artículo 23 de la Carta Social Europea (creada en 1961, revisada en 1996) ampara el derecho de las personas de edad avanzada a la protección social. Interpretando dicha declaración respecto al Salario Mínimo Interprofesional (SMI), se estima que la pensión mínima en el Estado español debería ser de $1.080 €$ mensuales. Esa demanda, proclamada el año 2016, antes de comenzar el conflicto actual, se ha convertido en todos los territorios en el elemento aglutinador que sustituye al rechazo del $0,25 \%$. De la fase de autodefensa se ha pasado a la ofensiva con una demanda difícil de asumir por cualquier gobierno. No obstante, algo se mueve en ese sentido cuando el 21/10/2018 un titular de Europa Press anunciaba: "El Pacto de Toledo pide indicadores a la Seguridad Social para calcular mejor la pensión minima».

Las demandas de los pensionistas se convirtieron en moneda de cambio entre PP y PNV durante la negociación de los PGE de 2018. Algo similar ocurre entre PNV y EH Bildu al negociar los presupuestos del País Vasco para el 2019. En ese sentido, la agencia Europa Press recogía el 20 de octubre de 2018 la siguiente valoración:

El PNV cree «complicado» que pueda haber un acuerdo con EH Bildu sobre los Presupuestos vascos después de que la coalición soberanista haya pedido una inversión de 350 millones de euros para complementar las pensiones, cuando éstas no son competencia del Gobierno Vasco. Tras considerar que una «subida generalizada» debe reclamarla a Pedro Sánchez, ha asegurado que acceder a la exigencia de la coalición soberanista, supondría someter a los vascos a una doble tributación.

La demanda de EH Bildu está basada en los $1080 €$ de pensión mínima que reclaman los pensionistas, mientras que el PNV la cuestiona, conforme proclamaba el titular de Noticias de Gipuzkoa el 8 de mayo: "Urkullu no ve viable las pensiones minimas de 1.080 euros». Es un asunto de mayor alcance que la materia presupuestaria, pues ambas formaciones, nacionalistas moderados y radicales, incluyen en sus planes soberanistas un sistema de pensiones propio. El modelo del PNV son las Entidades de Previsión Social Voluntaria (EPSV). Se trata de planes de pensiones de empleo que son productos financieros. La alternativa de EH Bildu no está definida, se limitan a reclamar el complemento hasta $1.080 €$ en los presupuestos del País Vasco.

La demanda de EH Bildu llega al movimiento de pensionistas a través del documento publicado el 18/10/18 por asociaciones de Euskadi y de Navarra: "Reclamamos a los Gobiernos de Gasteiz e Iruña un reparto justo de la riqueza existente y que reconozcan una Pensión Minima de $1.080 € »$. Es una medida que no figura en la tabla reivindicativa del MPB. Caso de llevarse a efecto, supondría un agravio comparativo respecto a otros colectivos sociales con percepciones de RGI inferiores. 
El PNV niega la viabilidad de la pensión mínima de $1080 €$. También cuestiona el incremento de la cotización máxima que el Gobierno central estudia aplicar para aumentar la recaudación. Es una medida que sin llegar al «destope» (suprimir el límite superior de las cotizaciones) afecta a los sueldos altos.

\subsection{Plataforma reivindicativa básica del MPB}

- Revalorización de las pensiones según el IPC real, garantizada por ley.

- Reducir las desigualdades y la brecha de género, pensión mínima $1.080 €$.

- Derogación de reformas laborales lesivas para las pensiones actuales y futuras.

— Integración de las trabajadoras de hogar en el régimen general de la Seguridad Social.

- Suprimir las desgravaciones de los planes de pensiones de empleo (EPSV).

— Suprimir la penalización de las jubilaciones anticipadas no voluntarias.

\section{Defensa del bien común}

El Sistema Público de Pensiones es un modelo de reparto basado en la solidaridad intergeneracional e interterritorial. Constituye un mecanismo de redistribución de rentas. El método es válido, fallan las fuentes de financiación, la distribución de los recursos disponibles y la gestión. Resulta imprescindible incrementar los ingresos procedentes de las cotizaciones, dignificando las retribuciones y las condiciones laborales de trabajadores y trabajadoras en activo. Dejando esas materias para quienes analizan la legislación y la regulación del mercado de trabajo, vayamos a ese modelo colectivo. Con un sistema de financiación individual no cabe imaginar que se pueda alcanzar la cohesión social lograda por el movimiento de pensionistas.

La lucha en defensa de pensiones dignas se basa en las claves del Sistema Público de Pensiones: bien común repartido de forma solidaria. El modelo establece una causa única. Es preciso mostrar sus insuficiencias y defender sus potencialidades de forma conjunta. La distribución debe ser equitativa, por eso se reivindica una pensión mínima que reduzca las diferencias entre pensiones altas y bajas, entre hombres y mujeres. Solidaridad en el colectivo de pensionistas, también con las generaciones futuras, reclamando la derogación de las reformas laborales de 2011 y 2013. Solidaridad con otras causas: conflictos laborales, recortes sociales, desigualdad...

El PNV aspira a generalizar en Euskadi un modelo de pensiones mixto, dual. Así lo anunció el 26/07/18 un titular del diario Deia: "Remetería aboga 
por impulsar una EPSV para todos los trabajadores de Bizkaia». Tal proyecto no favorece al sistema público de pensiones ni beneficiaría al conjunto de los pensionistas. Se intensificaría lo que ocurre en la actualidad: parte de las retribuciones salariales dejan de cotizar a la Seguridad Social y se detraen recursos de las haciendas públicas a través de las desgravaciones fiscales. Los sindicatos que han contribuido a implantar las EPSV parece que ahora cambian de actitud. Cabe interpretarlo del comunicado de ELA publicado el 06/08/2018: "Tras el supuesto impulso a las EPSV hay un intento de rebajar la fiscalidad a las rentas más altas».

Los fondos de pensiones no convencen a la Ministra Magdalena Valerio. Es lo que se deduce de las declaraciones recogidas por la agencia Europa Press el 27/08/18 en la inauguración de los cursos de la Universidad de Verano de Baeza:

Este Gobierno apuesta por un sistema público de pensiones fuerte porque la inmensa mayoría de los trabajadores de este país no pueden confiar su suerte a tener una pensión en un futuro digna con un fondo de pensiones. Eso sería tomarles el pelo si tenemos en cuenta el nivel salarial.

\section{Rejuvenecer en la edad tardía}

En las concentraciones se ha dicho: "la lucha nos rejuvenece, alarga nuestra esperanza de vida». Esa expresión es fruto del sentimiento de pertenencia a un colectivo muy amplio, de millones de personas, que han llegado sentirse socialmente excluidas. Cuando tanta gente comparte un proyecto y aspiraciones en un lugar determinado, ese espacio adquiere carácter simbólico. Participar como sujeto activo, como protagonistas, en movilizaciones multitudinarias. Sentir el reconocimiento de gentes que pertenecen a generaciones más jóvenes. Sincerarse con quienes están alrededor en la concentración. Poder exponer casos particulares ante una cámara de televisión. Salir de la soledad que tantas veces acompaña a las personas de mayor edad. Compartir espacio físico, inquietudes, sentimientos, tiene efecto terapéutico, contribuye a mejorar la calidad de vida. La experiencia de los pensionistas constituye un fenómeno digno de estudio en dinámica de grupos y en sicología social.

Es la generación que sufrió la represión y las miserias del franquismo, conquistando las libertades y los derechos que hoy tenemos. Se trata de la gente que impulsó los movimientos sociales: obrero, estudiantil, ecologista, feminista o vecinal. Es un colectivo que en su juventud tuvo que soportar las penurias del trabajo asalariado en la industria o el campo, con tareas penosas y horarios cuartelarios. En el movimiento de pensionistas se daban las condiciones precisas para pasar de la sumisión a la indignación y a la acción directa: disciplina, tenacidad, experiencia y, por supuesto, tiempo libre. Si sorprendió el estallido del conflicto, 
no debería extrańar la capacidad para organizar el proceso reivindicativo. Es una experiencia para sentirse útil que favorece la autoestima. Un ejercicio físico y mental que fortalece y vivifica.

\section{De las coordinadoras de fábricas al movimiento de pensionistas}

No abundan los fenómenos sociales con las características del movimiento de pen-sionistas desarrollado en Bizkaia. En duración guarda similitud con la «Huelga de Bandas» (1966) que duró 163 días y con la huelga de las trabajadoras de residencias (2017), 370 jornadas de paro indefinido. Ambas luchas tuvieron lugar en Bizkaia. En el aspecto organizativo, no en el origen ni en las características del conflicto, el ejemplo más parecido es el de las coordinadoras obreras del periodo de la «transición política». El sindicato CCOO nació en aquella época como movimiento de base que posteriormente se transformó en organización piramidal.

El caso más significativo, en cuanto a la forma de estructurarse, no en otros aspectos, es la Coordinadora de Fábricas de Bizkaia (CFB) (septiembre de 1976). Surgió como respuesta solidaria a un asesinato policial que tuvo lugar en Hondarribia (Gipuzkoa). Adoptó la forma de movimiento asambleario, agrupando a 240 representantes de 150 empresas, con una plantilla global de 100.000 trabajadores. En el plazo de dos sema-nas la CFB convocó y se secundaron 5 huelgas generales. El Gobernador Civil reconoció su capacidad de interlocución, autorizando tres concentraciones. A Sestao acudieron 40.000 personas, 15.000 en Erandio, 5.000 a Basauri. Se logró liberar a los obreros detenidos durante las manifestaciones.

El modelo organizativo era similar al del MPB: concentraciones, equipos de coordinación, capacidad de movilización, liderazgo colectivo. La CFB fue un ensayo de democracia directa en un sistema político sin libertades. Las asambleas de fábrica eran decisorias, en ellas se elegían las delegaciones y se votaban a mano alzada las propuestas de movilización.

La CFB se diluyó al acabar el conflicto que la había motivado, pese a que algunos sectores intentaron mantenerla sin las condiciones de las que surgió. Algo similar podría ocurrir con el $\mathrm{MPB}$, si se pretendiese darle continuidad cuando concluya el conflicto. El modelo de las coordinadoras obreras no desapareció con la disolución de la CFB y la legalización de las organizaciones sindicales (abril de 1977), se expandió por las zonas fabriles y durante varios años, hasta la consolidación de los sindicatos, coexistían ambos sistemas de representación en una misma empresa.

Caso notable de cohabitación fue Coordinadora de Representantes de Trabajadores de AESA (septiembre de 1977), constituida al anunciarse la reconver- 
sión que una década después culminaría con el cierre de varios astilleros, entre ellos Euskalduna (junio de 1988). Dicha coordinadora, reconocida por la dirección de la empresa pública Astilleros Españoles S.A., recibida en los ministerios afectados por el conflicto, estaba formada por 26 delegados pertenecientes a 10 centros de trabajo, con plantilla global de 20.000 trabajadores (8.000 en Bizkaia). Para conocer detalles de esos episodios del movimiento obrero consultar en bibliografía los trabajos de Luis Alejos.

\section{El conflicto continúa, la lucha sigue}

El 18 de octubre de 2018 diversas plataformas de pensionistas del País Vasco y de Navarra reunidas en Vitoria/Gasteiz, acordaron convocar manifestaciones en las cuatro capitales el sábado 15 de diciembre, en vísperas de las festividades navideñas. En Bizkaia en esa fecha se cumplirán 11 meses de concentraciones semanales y será la séptima manifestación que se celebre en el mismo periodo de tiempo, destacando la movilización multitudinaria e intergeneracional que el 17 de mayo concentró en Bilbao a 115.000 personas, bloqueando las calles y plazas de la ciudad.

Las movilizaciones promovidas a escala estatal los días 24 y 27 de octubre por la red No + Precariedad, integrada por un centenar de colectivos, han logrado una participación notable. Esa confluencia de movimientos sociales, apoyada por algunos sindicatos y partidos de izquierda, saca a la calle el extenso y grave dilema de las desigualdades sociales, sintetizadas en cuatro reivindicaciones básicas: redistribuir riqueza, conquistar derechos, recuperar el planeta, vida digna. Son hechos que evidencian el auge de los movimientos sociales, en particular el de pensionistas, ampliamente representado en la manifestación del sábado 27 en Madrid.

Resulta paradójico que un siglo después de implantarse en el Estado español el Retiro Obrero Obligatorio (1919) que estableció la edad de jubilación a los 65 ańos, los y las pensionistas tengan que reclamar que se respete, entre otros derechos, la edad de jubilación instaurada hace 100 ańos. Aquél histórico acontecimiento tuvo lugar en una época convulsa, con un gobierno conservador, en un país que todavía negaba el voto a las mujeres. Tras el cambio de gobierno de junio de 2018, la Coordinadora Estatal (COESPE) impulsó una consigna que se ha convertido en patrimonio de todas las movilizaciones de pensionistas y que marca el rumbo de futuros acontecimientos: "Gobierne quien gobierne, las pensiones se defienden».

Las concentraciones se mantienen en el País Vasco y se generalizan en el conjunto del Estado. Bizkaia seguirá como referente, salvo que surjan conflictos internos por cualquiera de los motivos citados. Cabe suponer que prosegui- 
rán las movilizaciones hasta las elecciones de mayo del 2019 y que entretanto el Gobierno central hará algún gesto satisfactorio. Esa fecha de referencia pondrá a prueba el compromiso de los partidos políticos con las reivindicaciones del movimiento de pensionistas.

\section{Claves del conflicto}

1. Las concentraciones de Bilbao comenzaron el 15 de enero mediante convocatoria anónima. El MPB, grupo que coordina las acciones, surge de las concentraciones.

2. El detonador de las movilizaciones fue el $0,25 \%$, convertido en referente símbolo. Previsiblemente, a ningún gobierno se le ocurriría volver a implantarlo.

3. La inclusión en los PGE de la mejora de las pensiones en base al IPC real no tiene efecto desmovilizador. La alternativa al $0,25 \%$ es la pensión mínima de $1.080 €$.

4. El PNV, fuerza hegemónica en la CAV, niega la viabilidad de la pensión mínima de $1.080 €$. Su alternativa son las EPSV, incluidas en su proyecto soberanista.

5. Paradoja: donde mayor es el nivel de combatividad y de renta, se implantan planes privados de empleo (EPSV), considerados amenaza al sistema público de pensiones.

6. Las concentraciones de Bizkaia, el modelo organizativo del MPB, son un referente, tienen efecto llamada para el colectivo de pensionistas del conjunto del Estado.

7. Las movilizaciones podrían sucumbir por: a) protagonismo personal, b) desacuerdo sobre caja única de pensiones, a) pacto sindical que anule la demanda de $1.080 €$.

8. El movimiento de pensionistas aspira a seguir activo en las elecciones de 2019. Es previsible que el Gobierno haga algún gesto previo sobre pensiones mínimas.

9. El soporte del MPB son las concentraciones, sin ellas perdería legitimidad. No cabe descartar que al acabar las movilizaciones haya intentos de mantenerlo.

10. Sugerencia para proyecto de investigación: analizar las claves de este movimiento social, espontáneo, descentralizado y plural, no supeditado a partidos ni sindicatos. 


\section{Publicaciones citadas en el texto}

EtXezarreta, Miren (2013), «Las pensiones públicas en cuestión», Laberinto, n.o 40.

Ibarra, Pedro y Grau, Elena (2000), Anuario de Movimientos sociales. Una mirada sobre la red, Icaria Editorial y Getiko Fundazioa, Barcelona, 9-26.

SÁEnZ, Luis María (2011), «Pensiones, capitalismo y desigualdad», Lan Harremanak , 24, 139-164.

Zubiri, Ignacio (2015) «Cómo reformar las reformas de las pensiones... y el coste de no hacerlo", Lan Harremanak, 33, 259-287.

\section{Otras fuentes documentales}

Alejos, Luis (1977), «Las luchas de septiembre del 76 en Vizcaya», El Cárabo.

Alejos, Luis (2017), La amnistía del 77 y el movimiento obrero, Pensamiento Crítico.

Alejos, Luis (2018), seis artículos de opinión sobre pensiones, eldiarionorte.es

De la Fuente, Mikel, diversos artículos sobre pensiones, Viento Sur.

Etxezarreta, Miren, Iglesias Fernández, José, Idoate, Elena, Junyent, Joan (2009), Sin pensiones públicas, qué futuro? Seminario Economía Crítica, Icaria, Barcelona.

Navarro, Vicenç, Torres, Juan, Garzón, Alberto (2010), ¿Están en peligro las pensiones públicas? Manu Robles-Arangiz Institutua.

Portas, M. ${ }^{\text {a }}$ Victoria (2017), La sostenibilidad de las pensiones: ¿problema de mercado o problema político? Foro Ametzagaña.

Ruiz Cabezuelo, José Manuel (2015), Tesis doctoral Evolución de la pensión de jubilación: presente y futuro, Facultad de Ciencias Sociales y Jurídicas de Elche.

\section{Cursos de verano 2018}

Baeza: El futuro de las pensiones a debate: retos y apuntes para sus sostenibilidad, https:// cursosdeverano.unia.es/item/el-futuro-de-las-pensiones-a-debate-retos-y-alternativaspara-su-sostenibilidad.html

Donostia / San Sebastián: La sostenibilidad del actual sistema de pensiones, https://www.uik. eus/es/la-sostenibilidad-del-actual-sistema-de-pensiones\#panel2 